2019-03-19

On the geographies of hair: exploring

the entangled margins of the bordered

body

Holton, Mark

http://hdl.handle.net/10026.1/13458

10.1177/0309132519838055

Progress in Human Geography

SAGE Publications

All content in PEARL is protected by copyright law. Author manuscripts are made available in accordance with publisher policies. Please cite only the published version using the details provided on the item record or document. In the absence of an open licence (e.g. Creative Commons), permissions for further reuse of content should be sought from the publisher or author. 


\section{On the geographies of hair: exploring the entangled margins of the bordered body}

Holton, Mark (2019) - School of Geography, Earth, and Environmental Sciences, Plymouth University

Accepted - 24 February 2019 (embargo until 24 February 2020)

Cite this article: Holton, M. (2019). On the geographies of hair: exploring the entangled margins of the bordered body. Progress in Human Geography. DOI; $10.1177 / 19838055$

\section{Abstract}

This paper extends discussions of the geographies of the body by examining hair as a geographical lens that reimagines the body's borders. Hair is a key agent in producing and representing the body, specifically through the presences and absences of hair that influence, disturb, transform and transcend its margins. By examining the materialities, performances and discourses associated with how and where hair is situated (or not) on the body, this paper situates hair as a geographical prism that explores new frontiers of the bordered body, shapes corporeal understandings of appearance and projects identities and power well beyond its physical limits.

\section{Keywords}

Hair; bodies; materiality; borders; performance; geography

\section{Introduction}

This paper seeks to advance previous work on the geographies of the body to examine the role of hair as a new geographical prism through which to view the frontiers of the body as a bordered, marginal space. Feminist and poststructuralist geographers have long read bodies as discursive spaces through which social, cultural and political imaginations are expressed, encoded and deciphered through representations of the body (Butler, 1990; Longhurst, 1995; 1997). Here, understandings of bodies as central to discussions of space are founded upon notions of embodiment - the ways in which something is represented or expressed to make it tangible or identifiable. Yet while approaching bodies as forms of 
representation attends well to social constructivist interpretations of embodiment, in the last decade non-representational readings of bodies (Colls, 2012; Macpherson, 2010) have begun to complicate these rather rigid ways of interpreting bodies as texts to be read. Geographers in this vein have questioned the ability for bodies to be understood as solely representational and/or socially constructed, instead encouraging debate that attends to emotions and affects and understandings of bodies as processes of relational becomings (Bondi, 2005; Davidson and Bondi, 2004; Tolia-Kelly, 2006). As such, contemporary geographical scholarship reveals bodies to be bordered spaces, the movements of which are shaped by an array of emotional, affective, embodied and material responses (Abrahamsson and Simpson, 2011; Casanova and Jafar, 2013; Lloyd, 2014; Smith et al., 2016). Yet, beyond movement the form of the body is also bordered, being mediated and regulated through its relative size and shape, meaning bodies are bounded by the skin, flesh and volume, that define interpretations of '(un)acceptable' bodies (Colls and Evans, 2014; Evans, 2006). Crucially, these borders are contested through various formal, informal and social structures that marginalise or restrict the imagined or tangible performances of gendered, ethnic, aged, (dis)abled bodies in space (Magennis, 2010). Teather (2005: 1), for example, imagines the body as embarking on a journey that negotiates the "institutional fabric of social life", meaning, while bodies are central to how identities are defined and performed in places these are rarely fixed and are subject to negotiation, contestation and re-imagination (Longhurst, 1997; Simonsen, 2000). Moreover, in drawing upon Merleau Ponty's (1968) phenomenological approaches, Verhage (2014: 103) argues that through the intimate proximities of bodies "we do continually and simultaneously give shape to each other, sometimes violently, sometimes lovingly". Hence, bodywork has been examined through its 'fleshiness', as well as through the complex material, symbolic, emotional and affective dimensions that, as Butler (1990) claims, produces, as well as defines, differentiates and subjugates bodies in space.

In advancing this, I draw upon Haraway's (1985: 33) compelling rejection of the limitations of corporeal boundaries: "why should our bodies end at the skin, or include at best other beings encapsulated by skin?". While Haraway's question is designed to query the relationship between human and machine, I use it here as a metaphor to stimulate interpretations of how we might reconsider what constitutes 
the borders of the body as more fluid, permeable, opaque - transcendable even. This paper draws upon hair - the ubiquitous and seemingly innocuous substance that distinguishes us as mammalian and that many of us spend significant time, energy and money on taming, cutting, styling and removing - to make new contributions to discussions of the geographies of the body by examining how its presences (or absences) can influence, disturb, transform and even transcend the margins of the body.

'Why hair?' you might ask. 'What can hair tell us about bodies that other corporeal dimensions, like skin, have not already?'. While scholars have engaged seriously with the skin as an intimate and highly visible spatiality (Ahmed and Stacey, 2003; Connor, 2004; Price, 2012), my focus upon hair as a space that occupies the margins of the body takes a different approach, providing some unique inroads that emphasises hair as a key agent in the symbolic shaping of social and cultural presentations of the body and of corporeal identities. Engagements with hair are therefore becoming increasing important. Indeed, I learned from the review of this paper that Caroline Faria and Jeffrey Hoelle (2018) had convened a session at the 2018 American Association of Geographers' Annual Meeting in New Orleans that focused specifically on disturbing the nature/culture binaries associated with hair (incidentally, right at the same time I had submitted the first draft of this manuscript!). Interpreting various hairy and hairless sites of the body therefore provides context for how and why hair can contribute towards a re-imagination of bodies, developing what Lowe (2016: 73) argues as a "vocabulary of hair" that essentially gives voice to the matter that exists on our skin. Hair is therefore multiply-sited through various spatialities that represent different cultural, ethnic, racialised and gendered identities, and multi-scalar in that it is powerful, yet can also denote suppression, dysfunction and sickness. It can individualise, differentiate and categorise, as well as control and regulate behaviour. Hence, because of its materialities, its relationality, its symbolism, hair complicates the body's borders, creating spaces that are experienced, understood and produced simultaneously.

In terms of bordering, while Kwint (1999: 9) states that hair exists at the "dead margins of the self", along with fingernails and other excreta, I argue that these borders are lively spaces, meaning hair can be considered a material 'thing' with 
agency (Thrift, 2008). Moreover, Leach (1958: 160) posits hair as "a separable part of the body [...], a 'thing in itself'". My analysis seeks to extend Leach's statement though by arguing that hair exists simultaneously as matter of the body, and matter that transcends the boundaries of the body. These presences and absences of hair, depending on their context, situate it as either revered or reviled, indicating a rich variety of identity expressions, as well as offering insight into how the body as a political space is mediated and subverted.

To make sense of these multi-dimensional geographies of hair, the analysis for this paper is divided into three sections. First I question the materiality of hair, examining the contestations relating to it as a bodily substance that shapes appearance and identity work. This is important as problematising scientific assumptions of hair as 'natural' matter emphasises the issues surrounding how bodies can be bordered and subjugated spaces. Next I investigate how hair is socially and relationally produced in the context of gender and race, and how these generate power dimensions that affect how identities are practiced and performed at the borders of the body. Finally I explore the absences and presences of hair to explain some of the complex and contested connotations that can be attached to hair cutting, hair loss and hair removal and how these position the body's borders as fluid and permeable. These three dimensions, though not discrete from one another, offer some important new directions for research into geographies of the body. Interpreting these characteristics of hair therefore reveals hair to be a bodily substance that represents new frontiers in understanding the bordered body through its multi-scalar characteristics that both shapes our understanding of appearance as well projecting identities and power in ways that extend well beyond its corporeal limits.

\section{Matters of hair}

This section questions how, as a material substance, hair is imbued with power and positionality. This reading of materiality as the quality of being composed of matter (Butler, 1989) situates hair - through its intimacies - as a substance that shapes and produces identities and positionalities, yet in doing so can operate as an instrument that colonises and segregates the body. Delving inside the body itself helps to explain how its physical margins - the configuration of cells, proteins and chemicals that constitute hair's structural qualities - contributes towards understandings of 
affective bodily processes and consequently to the bordering of bodies. While I am not suggesting that hair is exempt from power or from positionality, it has, for centuries, been abstracted and presented in ways that position it as value free. For example, in its most primal form, hair, like other excreta has been viewed as a bodily by-product that operates as a covering for warmth; to protect against environmental damage; to channel sweat and trap water loss; and to be sexually attractive (Stenn, 2016). In these contexts hair is considered a neutral substance or a natural entity that requires the agency of individuals to tame or control it. This view is, of course, problematic and incorrect as it conjures essentialist interpretations of identity, particularly as the constituent components of hair - the scaly cuticle that determines hair's texture and shine; the protein-filled cortex of the hair shaft that provides structure and contains molecules that give hair its colour, shade and tone; the shape of the hair follicle that determines whether hair is curly or straight - all act as potent cultural signifiers that colonise and socially construct the body and its placement in society (Banks, 2000). Hence, hair, like skin, is socially relational and differentiated (Price, 2012), as well as being a highly visible cultural and political signifier of difference.

The social construction of hair as a materiality that experientially borders the body begins with hair texture - specifically the shape of the hair follicle as the space through which hair forms and grows. For context, hair follicles are not universally shaped and the diameter of each follicle will determine the overall shape of the hair shaft that grows from it, producing curly, wavy or straight hair. Hair follicles that are typically circular in diameter give hair a much straighter appearance as it grows from the skin. Those that are typically elliptical, give hair a straighter or wavier texture, whilst curlier hair is produced from follicles that are very elliptical, or even ribbon-like. While this may seem trivial, these textures have carried colonial geographical connotations for centuries, with scientific research using hair texture uncritically to denote and classify race and culture. In this vein, typically circular hair structures are associated mostly with straighter Asian hair, whilst elliptical or very elliptical hair fibre is associated with wavier Caucasian and curlier African hair types respectively (Vogt et al., 2008). William Ripley, in his 1898 study: The Racial Geography of Europe famously utilised this classificatory technique to differentiate and organise a cultural hierarchy among European populations according to the characteristics of the body: 
"The European races, as a whole, show signs of a secondary or derived origin; certain characteristics, especially the texture of the hair, lead us to class them as intermediate between the extreme primary types of the Asiatic and the negro races respectively" (1898: 306).

This simplistic classification of hair type, whilst shocking through a post-modern gaze, demonstrates how the social construction of hair contributes towards a colonisation of the body (it is no surprise that Ripley's findings were adopted by eugenicists and white nationalists). With links to scientific racism and environmental determinism, this biological rendering of hair is, of course, loaded and essentialist, ignoring the agency of the body and its position as socially produced, performed and regulated in different ways (Salih, 2007). Power is therefore an important vehicle in the production and domination of the bordered body (Verhage, 2014), with hair texture being utilised as a potent weapon in the categorisation and situation of difference and the Other, both in a symbolic and geographical sense. Hair texture and colour were infamously used during the Second World War as a way to classify, segregate and murder those considered to 'look' Jewish. Suedfeld et al. (2002) argue that these tacit forms of othering through the relational stereotyping of bodily appearance render individual identities anonymous - as sets of (un)desirable features that are associated with demographic groups, and that may have lethal consequences for entire populations. This positions the body, and by extension hair, as a weapon of technology which, as Foucault (1977) argues, is performed upon the subjugated body in order to discipline it.

It is important, therefore to decolonise this essentialist and stigmatising bordering of hair. Thibaut et al. (2007) reject simplistic classifications of hair, arguing instead that hair fibre is heterogeneous, having material shape memory that is independent of ethnic origin. They suggest that the composition of curly hair is not discrete but exists among both Caucasian and African hair types. Here, hair texture can be considered dynamic, being programmed through the curvature of the bulb itself, with curlier hair having a retrocurvature (a backwards bend) that influences the overall appearance of each individual hair from birth (Thibaut et al., 2005). Beyond genetic influences, Westgate et al. (2017) propose that the hair follicle can temporarily mutate through drug regimes (e.g. cancer treatments) or after pregnancy as part of the shedding 
process, or be permanently changed through scarring. Hence, problematising the stereotypical depictions of hair classifications considers the power of imagined representations of hair upon how the body is (re)produced. So, while hair is a prism through which to view social identities, it must be considered in more heterogeneous and nuanced ways that counter such simplistic and essentialist meanings. In drawing upon Husserl's phenomenological understanding of the body as an assemblage of psycho-physical processes, Behnke (2010) argues that the lived experience of the body positions it as neither natural nor social. Considering hair as agential highlights its position at the margins of the body as potentially enabling bodies to exist as spaces in-between these states. By this I mean that the action of bordering the body is enacted through the interwoven social and biological characteristics of hair, meaning hair is not static but has the capacity to (re)shape identities and positionalities through a combination of genetic, chemical, social and environmental influences.

Alongside hair texture, hair also contains affective and sensuous qualities. Again, this links to notions of the body as an assemblage of biological, social and cultural practises that affect (and are affected by) social, spatial and cultural contexts (Blackman, 2012). This situates hair as a performative substance that is experienced by the body and to understand this I focus briefly upon 'goose-bumps' - the muscle contractions that make hair stand on end when someone is frightened or aroused. The function of goose-bumps comes from a process called 'piloerection' whereby a release of adrenalin causes the arrector pili muscles surrounding the hair shaft to contract, making the hair stand perpendicular to the skin. This simple bodily function provides a dynamic example of how the affective materiality of hair is, quite literally, performed at the margins of the body. As Anderson and Wylie (2009) infer, the body is not inert but is perceptive and sensual, acting and reacting to a variety of environmental rhythms. More broadly, this is evident through the tactile relationships people have with hair - the touching, ruffling and running of fingers through hair; playing with (others) hair and the movement of hair - and the rhythms and fluidity caught up in these processes that gives hair personality through a mixture of aesthetics and intimacies (McCracken, 1996). This has implications for how bodies are bordered, and Blackman (2012) states that the notion of the definitive body has been superseded by the differentiated body, a complex entanglement of 
psychological, biological, social and ideological characteristics. Yet, through this muddle, hair takes on charismatic qualities that makes it a space imbued with affect and emotion. As Holmes (2018) posits, hair has agency, and in the eyes of the wearer hair certainly 'does things' (it sticks up, it gets greasy, it goes frizzy, etc.), implying the social meaning and individualistic significance of hair are performed at the borders of the body. Here, bodies have an enduring capacity to subjectively respond to everyday practices (Abrahamsson and Simpson, 2011), further supporting this need to "rethink the limits of the body, its capacities and thresholds" (Wilson, 2017: 456), particularly in relation to how bodies are performed and encountered.

What makes hair distinctive though is that it grows, meaning identities are not fixed in space and time and may be (re)shaped to complement adaptive identity expressions throughout the lifecourse. While head and body hair may form through unique sets of biological processes, we as agents are capable of altering or subverting its materialities through various forms of modification that (re)form and (re)frame the borders of the body. Body alteration has been reflected upon extensively in terms of tattooing, piercing, branding, scarring etc., as well as through amputation, the use of prosthesis and the bodywork involved in weight-loss/gain, fasting, body-building etc. (Featherstone, 2003). Modification is therefore an intensely emotional expression of bodily alteration that articulates identities, fashion trends and social (non)conformities across a broad spectrum. Pitts (2000: 443) argues that "body modification [is] a practice imbued with agency by subjects", in that it expresses a visible public identity that subverts acceptable social norms. Yet it is the aesthetic disturbances that are felt when presented with alternative or transgressive bodies that is interesting here, particularly in relation to the ideological contexts of producing the 'perfect body'. The social and cultural significances of hair invites opportunities to explore this agency in more critical detail. Anderson (2018) offers some compelling temporalities to this argument through the context of male facial hair and shaving. He suggests that while fashions for facial hair have changed over the centuries they carry varying social, cultural and spiritual connotations - for example, the contestations between the clean-shaven face and the wearing of beards, sideburns and moustaches. Moreover, Oldstone-Moore (2016: 2), therefore proclaims men's "face[s] to be an index of maleness" - meaning masculinities that 
can be expressed and regulated through the cutting or shaping of facial hair are worn at the body's borders and act as material that borders the body. Yet, as Peterkin (2001) argues, while hair may arrive uninvited on the face at puberty for many men, the wearing (or not) of facial hair is socially and culturally regulated through societal norms, faith, fashion and taste (see: Lowe, 2016). What cuts through this is a sense that the topographical landscape of the body's borders - not just the head - can be shaped, contoured and transformed by hair. Specifically, the temporalities associated with styling, grooming and depilation presents some crucial differences to many other forms of body modification. Given that hair is a (mostly) renewable substance, its modification can be viewed as temporary - certainly relative to the permanence of tattoos and piercings. Holmes (2014: 95) argues then that hair carries with it multiple temporalities, making it a chameleon-like substance that is "all at once changing, changed, yet with constant features". Moreover, if hair can be considered a palimpsest it can also indicate how the borders of the body can themselves become layered. The cyclical nature of hair, through its growing, resting and shedding phases teases out these intimate geographies of the bordered body, providing opportunities to reshape and contour the body through these multidimensional qualities that effectively blur the boundaries of identity through its impermanence and temporalities.

\section{Hair and the socially and relationally produced body}

This next section extends the materialities of hair to examine how, through lenses of gender and race, hair contributes towards the social and relational production of the body's borders. Hair, in these contexts, can be viewed as a tool through which discourses of power, control and authority are inscribed upon, encountered by and used against bodies in space. Foucault (1977) argues that for the capitalist model of social life to function it needs compliant, 'docile bodies' that acquiesce the ideologies of authorities. Yet, this raises questions of how hair might endorse or subvert such corporeal conformities within society and how this contributes towards the political struggles involved in understanding gendered and racialised bodies. This is particularly important in the context of othering, specifically in relation to how the 'lived body' acts as a mechanism through which encounters with 'Other' bodies are mediated (Morris, 1982). Yet, while hair certainly operates as a component of the 
'socially shaped body' (Behnke, 2010), it contains synecdochical qualities that allow it to define a person's identity whilst simultaneously categorising entire demographic groups. This has implications for how hair might contribute towards the emergence and suppression of the body's borders and how these are recognised and mediated in society.

Hair is intrinsically entwined within the social and relational production of gender (Weitz, 2001). This was particularly prominent in Western societies during the Twentieth Century, being articulated through discourses of 'appropriate' hair length, style and colour. The normalisation of acceptable hair has contributed significantly to the problematic categorisation of gender and the gendered ordering of behaviour in schools and work places and presents hair as a device that organises and limits the body. Clarke and Bennett (2015) argue that we often inevitably fall into the trap of evaluating others according to standards of physical attractiveness that conform to societal norms and this is problematic when considering how the borders of the body are socially and relationally produced. For example, Hallpike (1969), drawing on hair in a Biblical sense, offers a simplistic but telling definition, suggesting hair that is cut relates to social control, while hair that is left long, or is 'untamed' constitutes being an outsider. Here, the relationality of gender - how gender makes sense in relation to the Other - brings gendered categories into being by constructing an illusion of 'naturalness' (Butler, 1990). In their study of masculinity performances in hairdressing salons, Robinson et al. (2011) propose that the stability of gender can be disturbed through subversive behaviours (e.g. men wearing their hair long or women cutting their hair short). They draw upon Brickell's (2005) reworking of performativity that incorporates Goffman's (1959) more reflexive understandings of identity to argue for the subjectivity of actors to be crucial in how gender is performed and received according to various (competing) social situations. These performances border the body through the relational experiences of 'acceptable' hair. For example, Gimlin's (1996) beautician participants speak of hair as a 'gendered enactment' through which the wearing of one's hair at different stages of the lifecourse can be inflected with particular anecdotal displays of identity: 
"[Women] wearing long hair during middle age hints at a falseness, an attempt to deceive, because, Donna [one of Gimlin's participants] says, long hair suits someone younger." (519)

This, rather cutting quote, demonstrates how the display of hair at the body's borders is interwoven with what seem to be socially acceptable gendered and aged performances. In this sense, (non)conformist hair presents a barrier of sorts that masks how identities may be managed, presented and practiced, blurring the subjectivities and agency of the wearer and fixing hair in time. Yet, this binary view of the existence of 'good hair', whereby the wearer is considered likely to engage in positive acts, and 'other' hairstyles that are associated with more transgressive behaviours (Lowe, 2016) is problematic. Weitz (2001) argues that gendered hair can be more dynamic, with women balancing the twin streams of accommodation and resistance when managing social situations that might influence both their position and status, as well how these are performed at the body's borders. Moreover, Yang's (2014) study of male trainee hairdressers in Taiwan provides further evidence of how the margins of the body can be disturbed. Like Robinson et al. (2011), Yang's participants challenge traditional notions of masculinities through performances of gender-fluidity (e.g. men playing with their hair or fixing their appearances in the salon mirror) that reinforce how alternative masculinities are displayed. Hence, the actions of conforming, or not, move hairstyles (and hairstyling routines and performances) beyond being simply fashion statements, to actively challenge dominant discourses of gendered identities and the borders of gendered bodies as opaque, fluid and permeable.

Like gender, hair plays a dynamic role in the construction and performance of race specifically in relation to the complex social, cultural, emotional and affective messages communicated through Black women's hair (Robinson, 2011) - that, as Kelley (1997) and Tate (2007) argue, positions Black hair not simply as a 'thing' in the world. This is particularly important as discourses surrounding Black hair have shifted it away from its cultural roots to re-signify it with slavery, colonialism and racism. In this context, hair contains symbolically constructed characteristics that relate to the perceived exoticism of 'Other' hair types and the 'taming' of 'wild' hair. Crucially, this presents Black hair as a space through which marginalisation and 
control are enacted and embodied through everyday hair management practices. The examples drawn upon here provide evidence for how the borders of the body are performed and experienced, literally becoming battlegrounds through which lines of identity, history and oppression are drawn. In November 2017, the Mexican-born, Kenyan raised actress Lupita Nyong'o, criticised the fashion magazine Grazia for altering the appearance of her hair for the front cover of the publication's winter edition. The magazine 'edited out' her naturally curly ponytail in an effort to achieve, what Nyong'o later Tweeted as "a more Eurocentric notion of what beautiful hair looks like" (Ruddick, 2017: np). This demonstrates the perpetuation (perhaps extension even) of what Simonsen (2000) argues as the subordination of culture through representations of the acceptable body, particularly in terms of how beauty is packaged, commodified and consumed. As Crewe (2001: 633) infers:

"The body - and particularly here the female body - is always inescapably encoded by cultural norms [whereby] the commodification of the body through the fashion and beauty industries presupposes that acutely self-conscious relation to the body which is attributed to femininity".

Crewe (ibid) goes on to argue that the body becomes engaged in a project of continual renewal and improvement through which the media perpetuates 'mythical stereotypes' of female perfection by way of highlighting and demonising the inadequacies of Other bodies. This is writ large within the context of Black hair, in which its treatment and appearance generate highly divisive and contested debates of how bodies 'should' be performed. Mercer (2000: 117), for example, argues that discourses surrounding Black hair have "sparked off a range of everyday critiques on the cultural politics of 'race' and 'aesthetics'" that accuses those who chemically relax their hair of 'deracialising' the ethnic body and 'becoming White'. The relaxing of Black hair especially is a contentious subject, comprising a set of arguments with many different and competing dimensions. Alongside cultural politics, straightening hair has been viewed as a practical solution for family life - particularly for children (Bordo, 2008); a marker of moving from childhood into adolescence or womanhood (Thompson, 2008); or a way of embodying cosmopolitanism by "look[ing] smart" (Faria, 2014: 324). Indeed, Linda Hardnett (cited in Ebong, 2001: 78) succinctly 
protests against notions of selling out in her poem If Hair Makes Me Black I Must Be Purple:

"Yes, my hair is

Straight

But that don't mean that I ain't

Black

Nor proud

All it means is that my is hair is

Straight".

Yet, these interpretations are in themselves social constructs, and as Thompson (2009: 831) articulates "[f]or the vast majority of Black women, hair is not just hair; it contains emotive qualities that are linked to one's lived experience". Hence, while the relaxing of hair may have practical benefits, the role of chemicals, products, equipment, etc. in shaping everyday bodily performances has implications for how the body is mediated, controlled and ordered in society and how hair is experienced as marginalised by the wearer. This links back to the earlier discussions of how 'good' and 'bad' hair is produced. As Robinson (2011) and Nichols (2013) argue, the practices involved in Black female hair (and body) maintenance outlined above emphasises how the expectations of the 'White body' project (i.e. of projecting White female beauty as the aspirational norm) by extension visibly, emotionally, and socially inscribes and controls Other(ed) bodies as marginal and bordered.

Notwithstanding this, when considering the body as a bordered space there remains plenty of discussion that frames 'natural' Black hair as a form of resistance against oppressive white beauty norms. A participant in Tarlo's (2016: 144) study states that: "we're not just battling against chemicals but against other people, our own families and the comments of people in the street", alluding to the psychogeographical implications involved in viewing hair as a relational set of internal and external symbolisms that are enacted at the margins of the body. As Banks (2000: 49) emphasises, while claims may be made to manageability, once this moves from the body and into the social realm, hair can "[go] beyond the mere act of combing" to produce feelings of stigma and self-hatred through wider constructions of beauty. These notions of hair as (de)limiting gendered and racialised bodies positions it as a 
significant agent in the relational production of bodies through various emotional and affective forms of contact with the social world. This has consequences for the bordering of the body, particularly as Ahmed (2013: 2) argues that national borders are repeatedly (and metaphorically) connected with the intimacy of the skin, in ways that suggest bodies are "soft, weak, porous and easily shaped or even bruised by the proximity of others".

\section{Absences and presences - hair at the margins...and beyond}

This final section focuses upon the presences and absences of hair that symbolically, politically and emotionally (re)produce the body and provides important dimensions in understanding the implications for how the borders of the body may be considered fluid and permeable. For example Dawney's (2011) reading of embodied imaginations explains how the 'historied body' has capacities to act in accordance with its imaginary experience of the world. This alludes to the power and agency of hair in defining nations, races, cultures and ethnicities through its existence (or not) at or beyond the borders of the body. These notions of presences and absences first relate to the conflicting senses of desire and revulsion that may result from hair existing 'away' from the body. For many, cut hair (trimmings) are considered waste, as a by-product - as dirt or 'matter out of place' (Douglas, 1966). While the removal of hair (and conversely the presences of unwanted hair) can be viewed as contravening the ordering of space, cut hair can take on quite contrasting identities once it is removed from the margins of the body ${ }^{1}$. Hair may, in some ways, lose material value when it is cut, becoming a consumable product to be disposed of. Yet, beyond waste, hair contains other dimensions, in that cut locks may also be agential, being ascribed symbolic value that connect loved ones over space and time. Holm (2004) writes of the fashion for mourning jewellery in the $18^{\text {th }}$ Century through which locks of hair were encapsulated within lockets and brooches worn about the body. This act of wearing the artefacts of loved ones provides social, cultural and material linkages to what Leder (1990) conceptualises as the 'absent body', essentially the existence of the body outside of its lived realities. This transcendence of the lived body to the object body - to an artefact that is imbued with intimate identities - is

\footnotetext{
${ }^{1} \mathrm{~A}$ comparative exploration of the geopolitical perspectives of cut hair was present by Caroline Faria and Mike Dimpfl (2018) at the 2018 American Association of Geographers' Annual Meeting in New Orleans.
} 
therefore viewed and mediated from a distance. Yet, this geographical 'distancing' of hair from the borders of the body may be problematic as hair in this sense can be thought of as stripped of its social identities. Its deeply interpersonal value means it becomes "necessarily anonymous to all but its intended bearer" (Holm, 2004: 141). More contemporary examples demonstrate how the purchasing, possessing and ownership of one's hair by another adds extra layers of complexity to these notions of the body's borders as malleable and transcendable. In 2011, a lock of the singer Justin Bieber's hair was sold for more than $£ 25,000$ in a charity auction on Ebay. The lock of approximately 200, one-inch hairs was encapsulated in a plastic container and was autographed by Bieber for authenticity (Telegraph, 2011). While the purchasing, and indeed reifying, of another's hair may appear odd (for context, Lowe (2016) writes that there exist countless locks of hair in religious sites around the world that purportedly belonged to the prophet Mohammed that worshipers are encouraged to kiss) this example positions hair as more than simply waste or a memory. Through ownership, a lock of hair can take on its own personal identities, perhaps presenting an imbricated borderland of sorts, an area of overlap between the bodies of the provider and of the recipient. This suggests that cut hair may become an imagined entity in itself, albeit in the form of a relic of another's body, that possesses considerable emotional value, and that may instil some potentially quite disturbing interpersonal connections between supplier and receiver. These examples of hair operating away from the borders of the body may therefore imply its capacity to be imbued with supernatural qualities. This extends Miller's (1982) notion of the fetishisation of hair by proposing that through this diffusion of the borders of bodies, hair becomes imbued with unique personalities and identities that mark it as a multiplicious substance - as both cherished and disposable, beautiful and dirty, memorable and anonymous.

Beyond notions of consensual cutting, hair absences, particularly through the forced removal of hair, provide evidence of more unsettling hair practices that relate to how biopolitical process of suppression and control are performed at the borders of the body. Foucault (1986: 140) argues that society has witnessed "an explosion of numerous and diverse techniques for achieving the subjugation of bodies and the control of populations" and hair, through its materialities, its social construction and its relational positioning, has played a central role in achieving this. This echoes 
Suedfeld et al.'s (2002) notions of stigma and stereotyping that infer hair as occupying a geo-political space through which racist and sexist forms of cultural stereotyping through hair colour and texture are performed. As a practice of bordering other bodies, hair becomes a technology of war and through its removal a symbol of control that dehumanises the subject. Examples of this are littered through history. Byrd and Tharps (2001) and Thompson (2008) recount the indignities and erasure of cultural identities experienced by West African's during the slave trade whose heads were shaved as they were cargoed to the Americas. Ephgrave (2016: 22) writes on the dehumanisation of Jewish women during the Holocaust whose heads were forcibly shaved and the subsequent degradation this caused through the loss of individual, feminine and cultural identities whereby "[a]ge and other personal differences melt away". What these practices of forcible hair removal demonstrate is a capacity to re-inscribe other bodies as powerless and vulnerable. While Butler (1993) argues that gender and sex are written onto our bodies in complex ways, the process of forcibly removing hair attacks this sense of identity, exposing the vulnerable margins of the body, thus rendering it 'identity-less' (Ephgrave, 2016). Lowe's (2016) depiction of Samuel Mullet who, in 2015 was convicted of federal hate crimes in the US state of Ohio for the hacking off of the beards and head-hair of members of the Amish community contextualises this further. This story has significance for understanding the cultural implications of bordering other bodies as uncut hair (both beard and head-hair) carries great spiritual importance among the Amish faith. As Lowe (ibid: 61) argues, the action here of forcibly cutting hair meant that Mullet and his gang were essentially:

"[...] judging, sentencing and punishing their victims, whose disfiguration, while only temporary and largely symbolic, was uniquely humiliating within their closed society".

Humiliation is fundamental in understanding how the multi-scalar power of hair specifically its removal - disturbs the margins of the body as acceptable and/or accepted. Here, the forced removal of hair acts as a mechanism through which the threshold of the body can be transcended, and whereby the power of the individual is rescinded through violence and humiliation. This is multiply scaled from the individual up to the nation state and as Moisi (2010: 57) argues: "[w]hen it is 
transcended and mastered, humiliation acts on nations as it does on individuals", meaning the act of humiliating another's body through forcible hair removal not only inflicts pain on the person but inflicts a symbolic act of defilement upon entire communities, states, nations and cultures. This subsequently reimagines the body as 'becoming' the border - as a visual representation of its (un)acceptability in space.

Furthering these forced absences, the presences of hair upon the seemingly 'unconventional' margins of the female body (e.g. the legs, armpits, face or pubic area) can produce similarly shocking examples of contestation, disgust and violence against women. In contrast to the value attached to head-hair, through a contemporary Western capitalist lens feminine body hair is characterised as unwanted, or as an excessive or needless substance. Lesnik-Oberstein (2006) describes body hair as the 'last taboo' of women's bodies, insofar as attempts to raise meaningful discourses of body hair are often met with silence or aggression. In October 2017, the Swedish model Arvida Byström posted a photograph on the social media site Instagram of her wearing a pair of Adidas trainers. In the image, Byström's unshaven legs were prominently displayed and in a resulting set of messages, the model reported being sent threats of rape for apparently contravening the social norms of the body:

"Me being such an abled, white, cis[gender $]^{2}$ body with its only nonconforming feature being a lil [sic] leg hair [...] literally l've been getting rape threats in my DM [direct message] inbox" (Kahn, 2017: np).

What is important to note here is that feminine body hair (alongside weight, image, appearance etc.) is articulated through patriarchal ideologies of female perfection that are designed to regulate and control the body - essentially creating bodies bordered by others. There are stark differences here between the acceptability of the placement of non-head hair on men's and women's bodies. Oldstone-Moore (2016: 2), for example, proclaims that for men "the language of facial hair [is] built on the contrast of shaved and unshaved". For women though, these binary terms clearly and unevenly - weigh shaving as a positive act against the negative connotations of not shaving (Torien and Wilkinson, 2004). This adds to the normalisation of female

\footnotetext{
${ }^{2}$ Cisgender refers to people whose gender identity matches the sex that they were assigned at birth.
} 
body hair removal in Western contexts (Torien and Wilkinson, 2003), alluding to notions of the civilised body and the conformist 'hairless ideal' (Terry and Braun, 2013) that naturalises hair removal among women. Indeed, MacDonald (2006) suggests that media images of hair removal never focus on the hair itself ${ }^{3}$, depicting the shaving or depilation of already smooth skin, further fetishising hairlessness as natural. Moreover, Lesnik-Oberstein (2006) argues that feminine body hair is unique in producing simultaneous and contradictory reactions, being at once meaningless, in that it is depicted only in the context of removal, and meaningful, in that it produces discourses that forbid its appearance on the body. This implies unequal interpretations of the propriety of the body as a bordered space. As Merleau-Ponty (1968) writes, the body does not belong exclusively to either the subject or the world, insofar as they are mutually relational - the body is an intertwined state between the perceiver and the perceived. Yet, in the context of women's body hair, this renders the margins of lived bodies invisible - in that bodies can be recognised as taken-forgranted, or normal, only when they conform to the norms of society (Morris, 1982). The terrain of the smooth body therefore becomes fetishised against the disturbances of troublesome hair.

The final dimension within this section examines the implications for hair loss upon how the body's borders are physically experienced. While this draws comparisons with the earlier symbolisms associated with non-consensual hair removal, this discussion moves on to examine how the process of 'losing' hair - the absence of hair as a consequence of biological or medical issues - may impact upon how 'different' bodies are viewed, performed and bordered. Hair loss takes on many guises, the most common of which being androgenetic alopecia, a permanent form of baldness more commonly referred to as male/female-pattern baldness, and alopecia areata, or 'spot baldness', an often temporary condition whereby hair loss may occur from some or all areas of the body. While androgenetic alopecia in men is a combination of genetics and hormones (the cause among women is unknown), alopecia areata is autoimmune, meaning it is a response of the body against its own healthy cells and tissues (Vary, 2015). To be clear, alopecia areata is not a dysfunction of the hair follicle - indeed hair will still grow and perform the cycle of

\footnotetext{
3 In July 2018 the US razor company Billie were the first to depict women with body hair in their advertisements (Belam, 2018).
} 
resting and shedding as normal - the issue is with the body itself and its failure to recognise its own cells. This provides context for how the bordering of the body is a function of the body that is then performed at the margins of the body. While the diagnosis, treatment and duration of these forms of hair loss differ greatly, the impact upon body image and self-esteem - specifically the ways in which the margins of the body are experienced - is profound (Cash et al., 1993). For example, Kranz's (2011) study of young men experiencing premature hair loss reveals how coping mechanisms, such as compensation (improving other aspects of appearance) and avoidance (pretending the hair loss is not happening), can be dysfunctional masculine approaches of dealing with hair loss that contribute to social stress.

In relation to the body's borders, Leder (1990) states that we only really ever notice our bodies when our understanding of wellbeing is disturbed. Leder infers such dysfunctional approaches to have implications for how the body's borders are expressed in space. For example, while self-awareness of the body can prompt support or repair, hair loss, in this context, can visibly signify the body as a neglected or decaying space (Merleau-Ponty, 1968), exacerbating the wearer's anxieties.

Moreover, absences of hair through cancer-related hair loss can challenge identities and senses of selfhood through the embodied stigma surrounding sickness and death among patients, particularly in relation to how the edges of the body are experienced and 'felt'. Ploug Hansen's (2007) account of women dealing with hair loss suggests the use of makeup, wigs and headwear become technologies that embody illness and treatment in an effort to help minimise, and perhaps even 'normalise', the effects of hair loss and retain a sense of status quo. Moreover, Rosman (2004) articulates how bodies can be bordered by illness and disease, acknowledging the dualisms involved in practices of displaying (or not) hair loss during treatment. This considers how the stigma associated with hair loss through treatment might disrupt how bodies are performed in both public (of divulging information and of receiving reactions from others) and private (of inhabiting/embodying hair loss) spheres. This links to Merleau-Ponty's (1968) discussions of visibility/invisibility, highlighting how gender operates as an important marker of how stigma may be embodied and performed through the body. Among Rosman's (2004) participants, women were more likely to camouflage their hair loss 
while men banalised it, or expressed it as an inevitable consequence of their treatment. This implies differences in how the stigma surrounding absence can be simultaneously publicly/privately, visibly/invisibly performed through, experienced by and worn on the body. Hence, absences of hair, and the subsequent revealing or camouflaging of such absences, provide visceral indicators of trauma that exist within the body, suggesting hair and the body as operating in interdependent, but not necessarily simultaneous ( nor complementary ways - influencing how identities, behaviours etc. are both performed and experienced.

\section{Conclusion}

Through this paper I have sought to advance discussions of the geographies of bodies by examining the role of hair as a new geographical prism through which the frontiers of the body as bordered, marginal spaces can be extended and reimagined. This analysis has demonstrated how the placement (or not) of hair on the body can produce powerful and emotive understandings of how bodily practices are socially and relationally produced. Comprehending the spatialities of hair reveals how its materialities, symbolism, subjectivity and agency provide unique articulations of how bodies are experienced, performed, projected and understood in space. This is expressed through the notion of hair as a borderland space that overlaps and influences the spatial and temporal dimensions that exist between the wearer and the observer. At the beginning of this paper I drew on Haraway's (1985: 33) question: "Why should our bodies end at the skin, or include at best other beings encapsulated by skin?" and this critique of hair as a more-than-bodily substance certainly conjures interpretations of the margins of the body as permeable, dynamic and transcendable. Drawing on Thrift's (2008) notion of glamour - the treatment of hair through the material qualities of hair-styling, the weaponisation of hair in the context of removing desirable hair or the placement of hair in undesirable places demonstrates how hair (loss) can manipulate the surface of the body in chameleonlike ways. These transformative qualities act as powerful identifiers that situate bodies at different stages of the lifecourse, as well as symbolically positioning them in time-periods through fashions, events and social expectations. In some ways these borders are expressed through the agency of the wearer but in others they are exerted through the power of society, or through the violence of an oppressor. Yet, 
while Holmes (2018) quite rightly asserts that hair holds its own agency through its identities, power and subjectivities, these must be negotiated carefully when determining the relational and somewhat imbricated ways in which bodies are situated in - and belong to - the world. The spaces at the edges of the body must therefore be considered not simply as two or three-dimensional but as containing multiple and unspecified dimensions within, and through, which bodily practices are performed.

Moreover, focusing on the supernatural qualities of hair, extends Leach's (1958: 140) argument that hair is "a separable part of the body [...], a 'thing in itself'", suggesting that hair's multi-scalar capacities contain multiple intersecting and conflicting spatialities and temporalities. This asserts hair as a bordering (and bordered) substance that both shapes embodied understandings of acceptable appearances and where/how these might be positioned. Hair (like clothes, make up, tattoos etc.) places individuals and bodies in space and time, yet also within various differentiated and relational social circumstances that, depending on the positionalities of the wearer or viewer, can galvanise or challenge senses of being in the world. Hair also projects identities and power in ways that extend well beyond what might be considered the limited borders of the body - the 'matter' of skin, flesh and bones. Exploring the absences and presences of hair through cutting, forcible removal and loss reveals hair to be integral in how sentient bodies are symbolically, politically and emotionally produced. Moreover, recognising absence and presence as geographical dimensions acknowledges the emotional work that is invested into hair as a substance with particular mobilities and agency. Hair has unique capacities to move beyond the borders of the body to take on different qualities associated with loss, theft, dirt, stigma etc., yet its highly contested (invisible even) positioning at the unconventional margins of the body emphasises discourses of the intertwined public/private body (Merleau-Ponty, 1968). This recognises the paradoxical nature of hair, being simultaneously fetishised and detested, as well as anonymous yet thoroughly humanised through its imaginative, material and symbolic qualities.

To close, I draw on Synnott (1987: 381) who writes: 
"Hair is perhaps our most powerful symbol of individual and group identity powerful first because it is physical and therefore extremely personal, and second because, although personal, it is also public rather than private".

This passage sums up the multiplicious dimensions of hair discussed throughout this paper. Synnott's assertions of the relationality of hair - its capacities to be simultaneously personal and public, individual and general, physical and symbolic get to the heart of this argument about the importance of focusing attention at the extreme edges of the body (and beyond). These discussions invite opportunities to explore further the intersectionalities involved in hair practices and performances in relation to sexuality, disability, age, faith and ethnicity and how hair can contribute towards the shaping of contemporary understandings of identity. Moreover, discourse is welcome that prompts further engagement with other modifiable bodily (e.g. eyebrows, teeth, fingernails, etc.) or sensual (e.g. through hearing-aids, spectacles, prosthesis, etc.) dimensions that position bodies in space and time. Notwithstanding this, beyond identity, more can be said of the contributions hair can make in shaping understandings of mobilities, migration and citizenship. I finish then with a recommendation that we attend to the body, not just as a subjective entity that transitions through space and time but as a persistent project of Self (and relational) identities that is continually re-inscribed, reshaped and re-sculpted.

\section{References}

Abrahamsson S and Simpson P (2011) The limits of the body: boundaries, capacities, thresholds. Social and Cultural Geography 12(4): 331-338.

Ahmed S (2013) The cultural politics of emotion. London: Routledge.

Ahmed S and Stacey J (eds) (2003) Thinking through the Skin. London: Routledge.

Anderson B and Wylie J (2009) On geography and materiality. Environment and planning A 41(2): 318-335. 
Anderson M (2018) Making facial hair modern: shaving and hirsuteness. In: Evans J and Withey A (eds) New perspectives on the history of facial hair: framing the face. London: Palgrave Macmillan, pp.109-129.

Banks I (2000) Hair matters: Beauty, power, and black women's consciousness. New York: NYU Press.

Behnke EA (2010) The socially shaped body and the critique of corporeal experience. In: Morris KJ (ed) Sartre on the Body. London: Palgrave Macmillan, pp.231-255.

Belam M (2018) Hair, hair: users applaud razor ad that shows women actually shaving. The Guardian. Available at:

https://www.theguardian.com/lifeandstyle/2018/jul/01/billie-womens-razors-hair-adshaving (accessed 30 November 2018).

Blackman L (2012) Immaterial bodies: affect, embodiment, mediation. London: SAGE.

Bondi L (2005) Making connections and thinking through emotions: between geography and psychotherapy. Transactions of the Institute of British Geographers, 30(4): 433-448.

Bordo S (2008) Cassie's hair. In: Alaimo S and Hekman SJ (eds) Material Feminisms. Bloomington: Indiana University Press, pp.400-424.

Brickell C (2005) Masculinities, performativity, and subversion: a sociological reappraisal. Men and Masculinities 8(1): 24-43.

Butler J (1990) Gender trouble: feminism and the subversion of identity. London: Routledge.

Butler J (1993) Bodies that matter: on the discursive limits of sex. London: Routledge.

Byrd A and Tharps L (2001) Hair story: Untangling the roots of Black hair in America. London: Palgrave Macmillan. 
Casanova E and Jafar A (eds) (2013) Bodies without borders. London: Palgrave Macmillan.

Cash TF, Price VH and Savin RC (1993) Psychological effects of androgenetic alopecia on women: comparisons with balding men and with female control subjects. Journal of the American Academy of Dermatology 29(4): 568-575.

Clarke LH and Bennett EV (2015) Gender, ageing and appearance. In: Twigg J and Martin W (eds) Routledge Handbook of Cultural Gerontology. London: Routledge, pp.133-140.

Colls R (2012) Feminism, bodily difference and non-representational geographies. Transactions of the Institute of British Geographers, 37(3): 430-445.

Colls R and Evans B (2014) Making space for fat bodies? A critical account of 'the obesogenic environment'. Progress in Human Geography, 38(6): 733-753.

Connor S (2004) The book of skin. New York: Cornell University Press.

Crewe $L$ (2001) The besieged body: geographies of retailing and consumption. Progress in Human Geography, 25(4): 629-640.

Dawney L (2011) Social imaginaries and therapeutic self-work: the ethics of the embodied imagination. The Sociological Review, 59(3): 535-552.

Davidson J and Bondi L (2004) Spatialising affect; affecting space: an introduction. Gender, Place \& Culture, 11(3): 373-374.

Douglas M (1966) Purity and danger: an analysis of concepts of pollution and taboo. London: Routledge.

Ebong I (ed) (2001) Black hair: art, style, and culture. Milford: Universe Publishing.

Ephgrave N (2016) On women's bodies: experiences of dehumanization during the Holocaust. Journal of Women's History, 28(2): 12-32.

Evans B (2006) 'Gluttony or sloth': critical geographies of bodies and morality in (anti) obesity policy. Area, 38(3): 259-267. 
Faria C (2014) Styling the nation: fear and desire in the South Sudanese beauty trade. Transactions of the Institute of British Geographers, 39(2): 318-330.

Faria $\mathrm{C}$ and Hoelle J (2018) Natural covers: comparative cultural geographies of hair and forests. American Association of Geographers Annual Meeting. New Orleans, USA, 10-14 April 2018.

Faria C and Dimpfl M (2018) Goulish, gorgeous, labored, loved: the geopolitics of hair. In Faria $\mathrm{C}$ and Hoelle $\mathrm{J}$ (convenors) Natural covers: comparative cultural geographies of hair and forests. American Association of Geographers Annual Meeting. New Orleans, USA, 10-14 April 2018.

Featherstone M (ed) (2000) Body modification. London: SAGE.

Foucault M (1977) Discipline and punishment. New York: Random House.

Foucault M (1986) The will to knowledge: the history of sexuality 1. London: Penguin.

Gimlin D (1996) Pamela's place: power and negotiation in the hair salon. Gender \& Society, 10(5): 505-526.

Goffman E (1959) The presentation of self in everyday life. London: Penguin Hallpike CR (1969) Social hair. Man, 4(2): 256-264.

Haraway DJ (1985) A manifesto for cyborgs: science, technology, and socialist feminism in the 1980s. In: Nicholson L (ed) Feminism / postmodernism. London: Routledge, pp.190-233.

Holm C (2004) Sentimental cuts: Eighteenth-century mourning jewelry with hair. Eighteenth-Century Studies, 38(1): 139-143.

Holmes $\mathrm{H}$ (2014) Chameleon hair: how hair's materiality affects its fashionability. Critical Studies in Fashion and Beauty, 5(1): 95-110.

Holmes $\mathrm{H}$ (2018) Transient productions; enduring encounters: the crafting of bodies and friendships in the hair salon. In Price $\mathrm{L}$ and Hawkins $\mathrm{H}$ (eds) Geographies of Making, Craft and Creativity. London: Routledge, pp.143-159. 
Kahn S (2017) Swedish model receives rape threats after posting image of hairy legs on Instagram. The Guardian. Available at:

https://www.independent.co.uk/news/world/europe/instagram-model-hairy-legs-rapethreats-arvida-bystr-m-a7987496.html (accessed 09 March 2018).

Kelley RD (1997) Nap time: historicizing the afro. Fashion Theory, 1(4): 339-351.

Kranz D (2011) Young men's coping with androgenetic alopecia: acceptance counts when hair gets thinner. Body image, 8(4): 343-348.

Kwint M (1999) Introduction. In Kwint M, Breward C and Aynsley J (eds) Material Memories. Oxford: Berg, pp.1-16.

Leach ER (1958) Magical hair. The Journal of the Royal Anthropological Institute of Great Britain and Ireland, 88(2): 147-164.

Leder D (1990) The absent body. Chicago: University of Chicago Press.

Lesnik-Oberstein K (2006) The last taboo: women and body hair. Oxford: Oxford University Press.

Longhurst R (1995) Viewpoint: the body and geography. Gender, Place \& Culture, 2(1): 97-106.

Longhurst R (1997) (Dis) embodied geographies. Progress in Human Geography, 21(4): 486-501.

Lowe S (2016) Hair. London: Bloomsbury.

Lloyd J (2014) Bodies over borders: the sized body and geographies of transnationalism. Gender, Place \& Culture, 21(1): 123-131.

McCracken G (1995) Big hair: a journey into the transformation of self. New York: The Overlook Press.

MacDonald A (2006) Hairs on the lens: female body hair on the screen. In: Lesnik-Oberstein K (ed) The last taboo: women and body hair. Oxford: Oxford University Press, pp.66-82. 
Macpherson H (2010) Non-representational approaches to body-landscape relations. Geography Compass, 4(1): 1-13.

Magennis C (2010) What does not respect borders: the troubled body and the" peace" process in Northern Irish fiction. The Canadian Journal of Irish Studies, 36(1): 89-107.

Mercer K (2000) Black hair/style politics. In: Owusu K (ed) Black British Culture and Society: A Text Reader. London: Routledge, pp.117-128.

Merleau-Ponty M (1968) The visible and the invisible: Followed by working notes. Evanston: Northwestern University Press.

Miller P (1982) Hair Jewelry as Fetish. In Browne RB (ed) Objects of Special Devotion: Fetishism in Popular Culture. Bowling Green, $\mathrm{OH}$ : Bowling Green University Popular Press, pp.89-106.

Moisi D (2010) The geopolitics of emotion: how cultures of fear, humiliation, and hope are reshaping the world. Toronto: First Anchor.

Morris P S (1982) Some patterns of identification and otherness. Journal of the British Society for Phenomenology, 13(3): 216-225.

Nichols EG (2013) 'Decent girls with good hair': beauty, morality and race in Venezuela. Feminist Theory, 14(2): 171-185.

Oldstone-Moore C (2015) Of beards and men: the revealing history of facial hair. Chicago: University of Chicago Press.

Peterkin A (2001) One thousand beards: a cultural history of facial hair. Vancouver: Arsenal Pulp Press.

Pitts V (2000) Visibly queer: body technologies and sexual politics. The Sociological Quarterly, 41(3): 443-463.

Ploug Hansen H (2007) Hair loss induced by chemotherapy: an anthropological study of women, cancer and rehabilitation. Anthropology \& Medicine, 14(1): 15-26. 
Price P L (2013) Race and ethnicity II: skin and other intimacies. Progress in Human Geography, 37(4): 578-586.

Ripley WZ (1898) The racial geography of Europe: a sociological study New York: D. Appleton and Co.

Robinson CL (2011) Hair as race: why "good hair" may be bad for Black females. Howard Journal of Communications, 22(4): 358-376.

Robinson V, Hall A and Hockey J (2011) Masculinities, sexualities, and the limits of subversion: being a man in hairdressing. Men and masculinities, 14(1): 31-50.

Rosman S (2004) Cancer and stigma: experience of patients with chemotherapyinduced alopecia. Patient education and counselling, 52(3): 333-339.

Ruddick G (2017) Lupita Nyong'o accuses Grazia of editing her hair to fit 'Eurocentric' ideals. The Guardian. Available at: https://www.theguardian.com/film/2017/nov/10/lupita-nyongo-grazia-editing-haireurocentric (04 December 2017).

Salih S (2007) On Judith Butler and performativity. In: Lovaas KE Jenkins MM (eds) Sexualities and communication in everyday life: A reader. London: SAGE, pp.55-68.

Simonsen K (2000) The body as battlefield. Transactions of the Institute of British Geographers, 25(1): 7-9.

Smith S, Swanson NW and Gökarıksel B (2016) Territory, bodies and borders. Area, 48(3): 258-261.

Stenn K (2016) Hair: a human history. London: Pegasus Books.

Suedfeld P, Paterson H, Soriano E and Zuvic S (2002) Lethal stereotypes: hair and eye color as survival characteristics during the Holocaust. Journal of Applied Social Psychology, 32(11): 2368-2376.

Synnott A (1987) Shame and glory: a sociology of hair. The British journal of sociology, 38(3): 381-413. 
Tarlo E (2016) Entanglement: the secret lives of hair. London: Oneworld Publications.

Tate S (2007) Black beauty: shade, hair and anti-racist aesthetics. Ethnic and racial studies, 30(2): 300-319.

Teather EK (2005) Introduction: Geographies of personal discovery. In Teather EK (ed) Embodied Geographies. London: Routledge, pp.15-40.

The Telegraph (2011) Justin Bieber's lock of hair sells for $£ 25,000$. Available at: https://www.telegraph.co.uk/culture/music/music-news/8361950/Justin-Biebers-lockof-hair-sells-for-25000.html (accessed 19th January 2018).

Thompson C (2008) Black women and identity: what's hair got to do with it. Michigan Feminist Studies, 22(1): 1-6.

Thompson C (2009) Black women, beauty, and hair as a matter of being. Women's Studies, 38(8): 831-856.

Terry G and Braun V (2013) To let hair be, or to not let hair be? Gender and body hair removal practices in Aotearoa/New Zealand. Body Image, 10(4): 599-606.

Thibaut S, Barbarat P, Leroy F and Bernard BA (2007) Human hair keratin network and curvature. International journal of dermatology, 46(1): 7-10.

Thibaut S, Gaillard O, Bouhanna P, Cannell DW and Bernard BA (2005) Human hair shape is programmed from the bulb. British Journal of Dermatology, 152(4): 632638.

Thrift N (2008) The material practices of glamour. Journal of Cultural Economy, 1(1): 9-23.

Toerien M and Wilkinson S (2003) Gender and body hair: constructing the feminine woman. Women's Studies International Forum, 26(4): 333-344).

Toerien M and Wilkinson S (2004) Exploring the depilation norm: a qualitative questionnaire study of women's body hair removal. Qualitative Research in Psychology, 1(1): 69-92. 
Tolia-Kelly DP (2006) Affect-an ethnocentric encounter? Exploring the 'universalist' imperative of emotional/affectual geographies. Area, 38(2): 213-217.

Vary JC Jr (2015) Selected disorders of skin appendages: acne, alopecia, hyperhidrosis. The Medical Clinics of North America (Review). 99(6): 1195-211

Verhage $\mathrm{F}$ (2014) Living with (out) borders: the intimacy of oppression. Emotion, Space and Society, 11: 96-105.

Vogt A, McElwee KJ and Blume-Peytavi U (2008) Biology of the hair follicle. In: Blume-Peytavi U, Whiting DA and Trüeb R M (eds) Hair growth and disorders. Berlin, Heidelberg: Springer, pp.1-22.

Weitz R (2001) Women and their hair: seeking power through resistance and accommodation. Gender \& Society, 15(5): 667-686.

Westgate GE, Ginger RS and Green MR (2017) The biology and genetics of curly hair. Experimental Dermatology, 26(6): 483-490.

Wilson HF (2017) On geography and encounter: bodies, borders, and difference. Progress in Human Geography, 41(4): 451-471.

Yang HC (2014) Flower boys on campus: performing and practicing masculinity. Journal of Gender Studies, 23(4): 391-408. 